\title{
Functional differentiation of sensory cells in the avian auditory periphery
}

\author{
Geoffrey A. Manley, Otto Gleich, Alexander Kaiser, and Jutta Brix \\ Institut für Zoologie der Technischen Universität München, Lichtenbergstrasse 4, D-8046 Garching, Federal Republic of Germany
}

Accepted August 22, 1988

Summary. Mammals and birds have independently developed different populations of sensory cells grouped across the width of their auditory papillae. Although in mammals there is clear evidence for disparate functions for the two hair-cell populations, the different anatomical pattern in birds has made comparisons difficult. In two species of birds, we have used single-fibre staining techniques to trace physiologically-characterized primary auditory nerve fibres to their peripheral synapses. As in mammals, acoustically-active afferent fibres of these birds innervate exclusively the neurally-lying group of hair cells in a 1:1 relationship, suggesting important parallels in the functional organization of the auditory papillae in these two vertebrate classes. In addition, we found a strong trend of the threshold to acoustic stimuli at the characteristic frequency across the width of the avian papilla.

\section{Introduction}

The structure of the auditory sensory epithelium in modern terrestrial vertebrates is very diverse (Lewis et al. 1985). Our present understanding of the evolution of the vertebrates indicates that the separate ancestors of mammals, of the archosaurs (Crocodilia and birds) and the modern lepidosaurs (reptiles such as lizards and snakes) diverged from the stem reptiles before the Permian period, i.e. about 300 million years ago (Carroll 1987). In the most primitive modern reptiles - the turtles and the Tuatara Sphenodon - there is only one type of hair cell in the auditory papilla. It is reasonable to suggest that, at the time of their independent

Abbreviations: $I H C$ inner hair cell(s); $O H C$ outer hair cell(s); $S H C$ short hair cell(s); THC tall hair cell(s) separation from the stem reptiles, all the ancestors of the above-mentioned groups possessed similar primitive hearing organs without specialized haircell populations. Thus, the distinct types of hair cells seen in modern birds and mammals arose independently in evolution.

\section{The comparability of hair-cell populations}

Hair-cell populations are distinguished on the basis of cell structure, position and innervation pattern. In mammals, there are clearly two populations of hair cells: one longitudinal row of neurally-lying inner hair cells (IHC) and three (occasionally more) rows of abneurally-lying outer hair cells (OHC). About 90 to $95 \%$ of afferent nerve fibres synapse only with IHC: each IHC synapses with up to 20 afferent fibres, each fibre contacting only a single hair cell (exclusive innervation). In contrast, only 5 to $10 \%$ of afferents contact the $\mathrm{OHC}$, even though they make up about $80 \%$ of the total hair-cell population (Spoendlin 1978). Each of these fibres contacts many $\mathrm{OHC}$ (non-exclusive innervation).

Unlike in the mammalian hearing organ, the hair cells of the avian papilla are not so clearly divided into two populations; some authors even see no justification on structural grounds for distinguishing more than one hair-cell type in avian papillae (Jahnke et al. 1969). The avian papilla actually shows a continuum of hair-cell structure from the tall hair cells (THC) on the neural (inner) side to the short hair cells (SHC) on the abneural side of the papilla. In general, however, depending on the criteria used to discriminate between haircell types, two to four intergrading hair-cell types have been recognized, i.e., the tall, intermediate, short and, less often, lenticular hair cells (Smith 1985). The tall hair cells have been distinguished 
from the short hair cells by their columnar shape and the different innervation pattern. They are found predominantly supported by the neural limbus (often termed the superior cartilaginous plate in birds) and, at the apical end of the basilar papilla, by the basilar membrane. In contrast, the short hair cells are wider than they are tall and have large cuticular plates. These cells occupy most of the space over the free basilar membrane. Intermediate cells are intermediate both in shape and in position. The actual distribution of these haircell types is species-specific, the most striking differences being found at the apical end (Smith 1985). Not all types have been recognized in all species and they are, unlike in the very similar papilla of the crocodilian Caiman (Leake 1977), frequently difficult to distinguish in a surface view.

Avian papillae also differ in some other respects from those of mammals:

- they are generally much shorter, but have a comparably large number of hair cells. Thus, there are many more cells in any one cross-section (up to $30-50$ at the apical end; Gleich and Manley 1988; Smith 1985).

- not all avian hair cells are abneurally oriented. Although early reports suggested that the birds showed at most the minor deviations from an abneural innervation as also seen in mammals (e.g. Takasaka and Smith 1971), this was an error. In the chick (Tilney et al. 1987), pigeon and starling (Gleich and Manley 1988) and the barn owl (Fischer et al. 1988) papillae, hair-cell orientation in the center of the apical area of the papilla is rotated up to $90^{\circ}$ towards the apex. The hair-cell orientation changes back to $0^{\circ}$ (i.e., abneural) towards both edges of the papilla.

Although the anatomical division into different hair-cell types in birds is not as clear-cut as in mammals, structural parallels do exist between the tall and short hair cells of birds and the inner and outer hair cells of mammals, respectively (Manley et al., in press). The evidence to date for this is:

- The relative position of the cell groups with respect to each other is the same. Both IHC and, in general, THC are not found over the free basilar membrane. Except for some apical THC, they are situated within the neural side of the papilla, which overlies the superior cartilaginous plate in birds and the spiral lamina in mammals (Smith 1985). This has, in the past, led some authors to use the mammalian terms IHC and $\mathrm{OHC}$ for the hair-cell groups of birds and crocodilians.

- The hair cells lying on the neural side of the papilla are regarded as being the less specialized in both vertebrate classes (Chandler 1984; Takasaka and Smith 1971).

- The THC and IHC receive a much stronger afferent innervation than the SHC and OHC. Although detailed studies in birds are still lacking, it is clear that, like IHC (Liberman 1982), THC are usually exclusively innervated, that is, their afferents synapse only with one single hair cell. According to von Düring et al. (1985), a single THC in birds receives between 1 and 4 afferent nerve fibres, the neural portion of the papilla showing the highest innervation density. In addition, there is little branching among THC afferents (Rebillard and Pujol 1983; Whitehead and Morest 1985a, b). $\mathrm{THC}$ near the zone of transition to $\mathrm{SHC}$ receive only one afferent fibre. Although Whitehead and Morest $(1985 \mathrm{a}, \mathrm{b})$ found in the chick embryo many afferents which penetrated between two THC and innervated both, this pattern is very seldom in our data. In contrast, SHC, like $\mathrm{OHC}$, are innervated non-exclusively by a relatively small percentage of the afferent fibers (mammal 5 to $10 \%$ ), which have small bouton-like synaptic endings (von Düring et al. 1985; Spoendlin 1978). A single afferent fibre contacts up to $6 \mathrm{SHC}$ (on average three). On the basis of innervational densities, von Düring et al. (1985) calculated that only $18 \%$ of afferent fibres in the starling innervate what they call SHC.

- The efferent innervation of both OHC and SHC is markedly stronger than that to THC or that contacting the afferent fibers of IHC, and the synaptic endings are much larger (Firbas and Müller 1983; Spoendlin 1978; Takasaka and Smith 1971). Also, in both cases, the innervation density of efferents is higher in the basal than in the apical half of the papilla.

- The ontogenetic development of the afferent and efferent innervation follows very similar patterns in birds and mammals (Fermin and Cohen 1984; Whitehead and Morest 1985a, b; Pujol et al. 1978). During early development, there is a reduction of the branching of afferent fibres, so that in the adult bird, fibres innervate either THC or SHC, but not both.

- Both SHC and OHC tend to be the most sensitive to noise damage (Cotanche et al. 1987; Liberman and Kiang 1978; Robertson 1982).

\section{There is a single population of acoustically-active afferent fibres}

The morphological parallels outlined above have not been matched by equivalent findings of similarities in the physiological responses of primary nerve fibers of mammals, birds or Caiman. A1- 
though the response activity of bird primary afferents certainly does resemble that of mammalian afferents in many respects, these similarities are, in general, features of all vertebrate auditory organs (tonotopic organization, frequency selectivity, etc.). There are both quantitative and qualitative differences in the activity patterns of primary auditory neurons of birds and mammals (Manley et al. 1985; Schermuly et al. 1983; Schermuly and Klinke 1985).

In spite of these differences in response properties, the available physiological data on the activity of primary auditory nerve fibres in birds and mammals suggest that in both cases there is only one physiologically-definable population of afferent fibres; that is, there is no consistent way of separating primary fibres according to their physiological responses into two populations corresponding to afferents from the two populations of hair cells (Manley 1983; Manley et al. 1985). In the cat, this paradox was explained by the finding that all acoustically-active afferent fibres innervate only one population of hair cells, the IHC (Liberman 1982). The fibres of the sparse afferent innervation of the OHC apparently have no spontaneous activity under normal recording conditions and do not respond to acoustic stimuli (Robertson 1984). In the caiman also, which has an auditory papilla very similar to that of birds, only one physiologicallydefinable fibre population was found (Klinke and Pause 1980). In Caiman, the afferent-fibre groups innervating the $\mathrm{THC}$ and $\mathrm{SHC}$ make up about $60 \%$ and $40 \%$ of the auditory nerve, respectively, and it seemed inconceivable that one of these large groups of afferents could simply be missed by the recording technique.

In mammals, investigations of otoacoustic emissions from the inner ear revealed that $\mathrm{OHC}$, instead of transmitting acoustic information to the brain, apparently have a function restricted to the organ of Corti as reverse, that is, electromechanical, transducers (e.g., Mountain 1986). It has been proposed that they actually amplify basilar-membrane displacement and thus increase the sensitivity of the hearing organ. The absence of responses in their afferent fibres could be explained if the fibres have another, e.g., a trophic, function. Is a division of labour of this kind typical of auditory papillae which show more than one type of hair cell? Even though otoacoustic emissions (which are thought to be manifestations of reverse transduction) with features similar to those of mammals have been reported from a bird species (Manley et al. 1987b) and the related Caiman (Klinke and Smolders 1984), they have also been found in a frog (probably from both papillae, Palmer and Wilson 1981). Thus, although otoacoustic emissions are not unique properties of hearing organs with specialized hair-cell populations, in such papillae one hair-cell population may be specialized as reverse transducers. The question remains as to whether such hearing organs also show a discrete restriction of auditory synaptic activity to one population of afferents. Such a parallel would be suggestive of a functional equivalence of hair-cell populations.

\section{Localization of acoustically-active afferents in the avian papilla}

To investigate the peripheral origin of acoustic activity recorded in the avian auditory nerve, we carried out two series of experiments staining and tracing physiologically-characterized primary afferents in the cochlear ganglion of starlings and 2-day and 21-day-old chicks. The surgical techniques have been previously described (Manley et al. 1985, 1987a). Cells were detected either by their spontaneous activity or their responses to white-noise search stimuli or both. In contrast to mammals, there is no population of avian afferents without spontaneous activity (Manley et al. 1985). Upon encounter, fibres were studied using a variety of acoustic stimuli. Generally, stimuli were presented using a computer-controlled system to cover a large matrix of frequency- and sound-pressurelevel combinations. The contours of the frequencyintensity tuning curves were determined from the responses to the test tones. Generally, one or two of the fibres which had been characterized were labelled using the horseradish peroxidase technique (chick; Manley et al. 1987a), or a cobalt technique which does not require intracellular recording conditions (starling; Köppl and Gleich 1988).

In the present paper, we describe important details of the distribution of fibre terminals along two dimensions of the hair-cell mosaic. We were particularly concerned not only to localize different frequency responses along the length of the papillae, but also to examine the question of a specialization of hair cells across the width.

\section{Distribution of characteristic frequencies along the papilla}

In whole mounts of the starling cochlea, we traced 20 single fibres and 14 small groups of afferents (2-6 fibres), in the chicks, 21 single afferents or groups of afferents to their synaptic terminations 


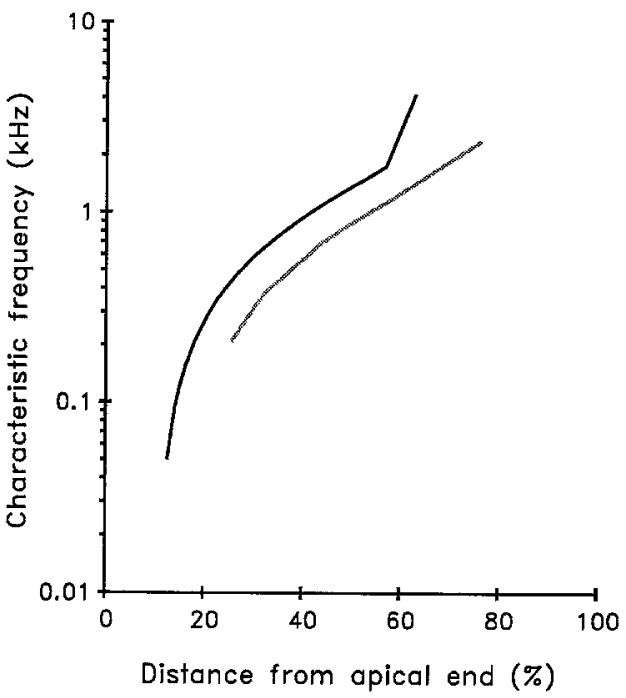

Fig. 1. Schematic illustration of the tonotopic organization of the basilar papilla of the starling (black line) and the posthatching chick (grey line). The curves are locally-weighted regressions (Cleveland 1979) based on 20 single-fibre and 14 small-group (2-6) fibre stains in the starling and 21 single afferents or groups of afferents in the young chick

on hair cells. Of these fibres, 25 and 15 , respectively, were subsequently localized in transverse sections of the papillae. In both species, a very similar tonotopic organization of the responses of the THC in the papilla was demonstrated, in which low-frequency octaves lie apical and occupy less space than high-frequency octaves. This pattern is common to many vertebrate hearing organs (Manley et al., in press). In the starling, the slope of the function relating place and $\mathrm{CF}$ in the low-frequency range is about $0.1 \mathrm{~mm} /$ octave, whereas at high frequencies it is near $0.6 \mathrm{~mm} /$ octave (Gleich, in press; Manley et al., in press). In the chicks, the tonotopic organization is indistinguishable at the two different ages (Manley et al. 1987a): compared to the starling for equivalent positions along the epithelium, it is shifted to lower frequencies; Fig. 1.

\section{How are active afferent fibres distributed between hair-cell groups?}

As it was not possible in our material to use more sophisticated criteria (such as details of the innervation pattern) for delimiting hair-cell populations, we designated as THC all those hair cells with a height/width ratio greater than one. With only two exceptions (see below), each afferent fibre only contacted one single THC (Fig. 2A, B). To describe the exact position of the hair cells receiving these afferent terminations, we counted the number ( $=$ rank) of each innervated hair cell across the row of hair cells in cross-sections, starting from the neural side of the papilla. Virtually all hair cells innervated by stained fibres had a rank of less than 15 , even though up to 35 hair cells could be found in any one cross-section (Gleich and Manley 1988; Fig. 2A). Using the above data on the tonotopic organization to represent the position of fibres along the length of the papillae, and using the number of hair cells across each papilla at each location, we constructed a normalized diagram illustrating the relative position of the individual innervated hair cells in two axes (Fig. 2B). It is obvious that in both species, with the two exceptions mentioned below, the innervated hair cells lie on the neural side of a line separating THC from SHC (1:1 ratio in Fig. 2B), even though the actual position of this line varies along the length of the papilla. With the exception of the apical end, where there are proportionately more THC, the hair cells innervated by the stained fibres are actually all within the neural half, because the surface area of the THC is much smaller than that of the SHC (see also Fig. 3; Gleich and Manley 1988).

Using the assumptions of von Düring et al. (1985), we estimated that about $13 \%$ of the afferents should innervate what we call SHC in the starling and chick. However, we found only two stained fibres $(=3.6 \%)$ innervating $\mathrm{SHC}$ : these were in the apical part of the starling papilla (fibres marked with arrowheads in Fig. 2A, B). The statistical probability of encountering so few abneural fibres ( 2 out of 55$)$ is very low $\left(\chi^{2}=4.092, P<\right.$ 0.05 ). The available anatomical data (Boord and Rasmussen 1963; Fermin and Cohen 1984; Whitehead and Morest 1985a, b; Smith 1985) give no indication that avian fibres are divided into two populations on the basis of their size and myelination, such as is seen in mammalian type I and type II fibres, so there is no reason to believe that SHC afferents are more difficult to record from. The two exceptional fibres mentioned above also had unusual response properties - they not only had high rate thresholds ( $>70 \mathrm{~dB}$ SPL) but also extremely flat, low-frequency tuning curves for which it was hardly possible to define a characteristic frequency. One of these fibres innervated about 6 hair cells and was the only branched fibre found. These two fibres resemble 'infrasound' fibres which innervate intermediate or short hair cells of the specialized (Gleich and Manley 1988) abneural area at the apex of the pigeon's papilla (Schermuly and Klinke, in press). They thus do not form part of the main, neural hair-cell group representing 


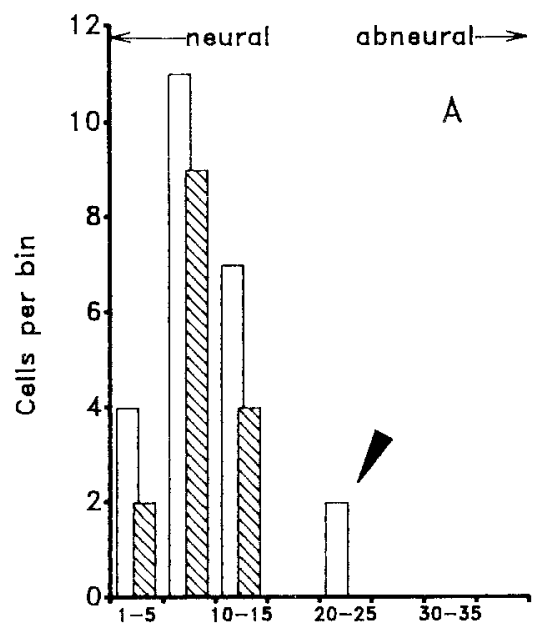

Hair-cell rank in cross-section

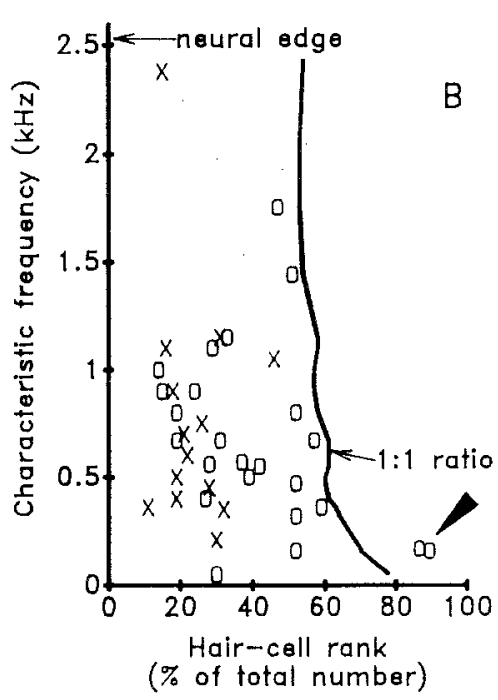

Fig. 2 A-C. Characteristics of avian primary auditory fibres as a function of the position of the innervated hair cells within the sensory epithelium. A Relative position of hair cells synapsing with labeled fibres over the width of the papilla in the starling and chicken. The rank indicates the location of the hair cell in cross-sections of the papilla, counting the hair cells from the neural side and placing them into groups of 5 cells. The two exceptional fibres are indicated by an arrowhead. $\square$ Starling; chicken. B Schematic diagram illustrating the localization of innervated bair cells over the surface of the papilla. The ordinate represents the characteristic frequencies of the individual fibres, the abscissa indicates their rank in the cross-sections. In order to compare the two species, where the total number of hair cells in one cross-section is different, the rank has been normalized. The thick line delineates the border between cells on the neural area, which have a length: width ratio of greater than 1, and those on the abneural area, which are shorter than this, in the starling. The 1:1 line for the chick would lie 5-10\% to the left. Only two fibres in the low-frequency, apical area (arrowhead) innervated hair cells abneural of this line. We consider only the rank of each hair cell, but not its corresponding width. Thus, because the surface area of THC is much smaller than that of SHC, in an actual surface-area map of the space on the bird papilla, the 1:1 line would lie much nearer to the neural edge. O Starling; $\times$ chicken. $C$ Correlation between the rate-response threshold at CF (threshold for an increase in discharge rate) for 12 fibres in the starling and their rank across the epithelium. In order to exclude effects due to threshold differences inherent in the form of the audiogram, only cells with CF between 0.6 and $1.8 \mathrm{kHz}$ are included. The line represents a simple linear regression. For threshold vs position across the papilla, $n=12, r=0.764, P<0.01$

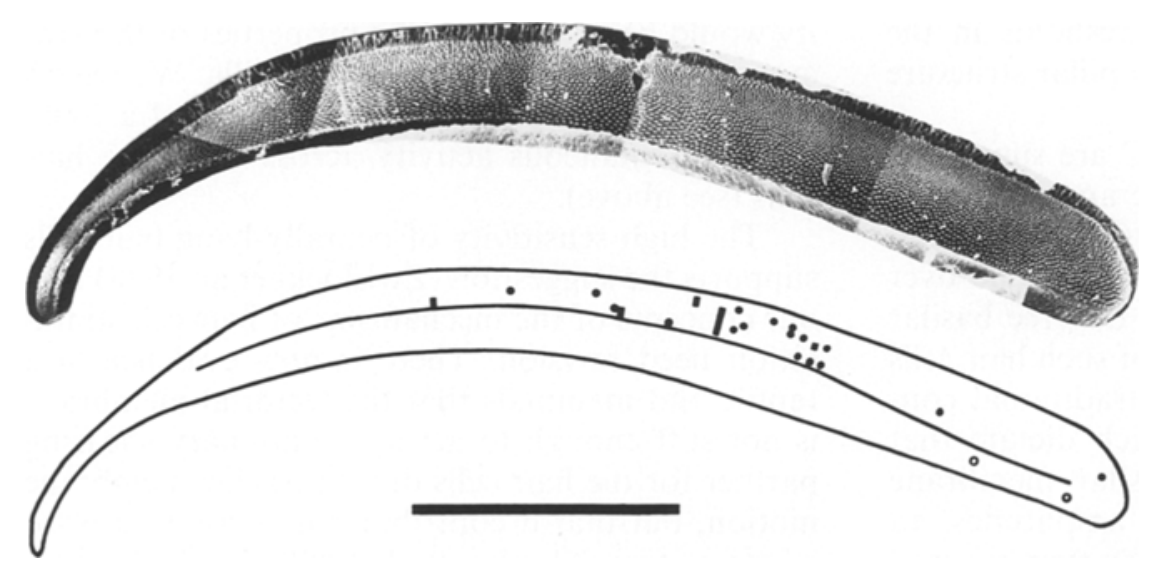

Fig. 3A, B. Schematic illustration of the position of stained afferent terminals within the hair-cell mosaic of the starling auditory papilla. A Scanning-electron micrograph of the upper surface of a starling papilla. Neural is to the top, apical to the right. B Outline of the papilla shown in A, with dots indicating the position of each hair cell singly innervated by stained afferent fibres. Squares and small bars indicate stains resulting in the staining of fibres to two to eight hair cells. The small open circles in the apical area indicate the innervation area of the two exceptional fibres (see text). The continuous line along the papilla illustrates the actual border between neurally-lying THC (hair cells are taller than wide) and SHC. Scale bar $500 \mu \mathrm{m}$ 
the 'normal' frequency map of the avian papilla and were not included in subsequent analyses.

\section{Response variation across the papillar width}

The avian THC area is much larger than the single row of IHC of mammals, making it possible in birds to examine the physiological properties of fibres synapsing at different positions across the papilla, but still within the group we define as THC. There is no trend with position either in the spontaneous activity or in the sharpness of tuning $\left(\mathrm{Q}_{10 \mathrm{~dB}}\right)$ of the fibres. However, there is a trend in the rate-response threshold at CF in the sample of 24 starling fibres, such that fibres synapsing on the most neurally-lying hair cells are the most sensitive to sound. To exclude effects from threshold differences due to the shape of the audiogram, we selected fibres in the CF range between 0.6 and $1.8 \mathrm{kHz}$, where the audiogram is quite flat (Kuhn et al. 1982). For this analysis, the data sample was only large enough in the starling, where a simple linear regression revealed a surprisingly strong threshold increase across the papilla (almost $6 \mathrm{~dB}$ / hair cell; Fig. 2C). Should the trend to increasing threshold continue through to fibres contacting SHC, they would have thresholds above 80 or $90 \mathrm{~dB}$ SPL, higher than we used in our experiments and not likely to be of great auditory significance to the bird. Large threshold differences between neural and medial fibres would explain why threshold ranges for afferent fibres in any one frequency region in birds can exceed $50 \mathrm{~dB}$ SPL (Manley et al. 1985). The high sensitivity correlates with the high density of afferent innervation of the most neurally-lying THC (see above). Interestingly, there is also a large spread of thresholds in the caiman, which has a very similar papillar structure (Klinke and Pause 1980).

In birds, almost all of the THC are supported by the superior cartilaginous plate and do not lie over the free basilar membrane (Takasaka and Smith 1971). In mammals, the IHC also lie over the inner bony edge and not over the free basilar membrane. The higher sensitivity of such hair cells is contrary to intuition based on traditional concepts in auditory physiology, which dictate that hair cells lying over the free basilar membrane (with the largest displacement amplitudes to sound) should be more sensitive. However, the motion of the basilar membrane in mammals is strongly influenced by mechanical activity of the $\mathrm{OHC}$ themselves, and as such is at least partially a secondary phenomenon. Very little is known about the mechanisms of hair-cell stimulation in birds.

In contrast to statements found in many publications, the arrangement of hair-cell orientations in the bird basilar papilla is by no means as regular as that of mammals. Whereas there is no bidirectionality as in lizards, there are substantial deviations from a purely abneural orientation (Fischer et al. 1988; Gleich and Manley 1988; Tilney et al. 1987). Thus, the regularly abneural orientation pattern described by Takasaka and Smith (1971, their Fig. 35) for the pigeon's papilla (based on sectioned material) is incorrect. Indeed, the deviation of hair cell bundle orientation from the abneural direction for hair cells in the middle of the papilla increases from the base to the apex, such that apical hair-cell bundles have an orientation which deviates up to $90^{\circ}$ from abneural. If we assume a purely radial shear motion of the tectorial membrane and a cosine function for the effectiveness of stimulation of the hair-cell bundle (Hudspeth and Corey 1977), this variation in orientation would certainly influence the threshold sensitivity of different hair cells placed across the papilla. However, using these assumptions, our calculations show that the maximal rotation of bundles in the frequency region investigated $\left(<70^{\circ}\right)$ would only be sufficient to produce a threshold difference of about $1-2 \mathrm{~dB}$ per hair cell, as compared to the almost $6 \mathrm{~dB}$ per hair cell we find. On the other hand, the SHC may receive similar mechanical input to that of THC and produce comparable electrical signals, but their receptor potentials may be transformed into a mechanical response rather than, or as well as, resulting in a transmitter output. An additional mechanism influencing sensitivity would be a change in the properties of the synapses of the afferents across the papilla. We regard this as unlikely, in view of the absence of a trend in the spontaneous activity across the same hair cells (see above).

The high sensitivity of neurally-lying hair cells supports the suggestion (Zwislocki et al. 1988) that our concepts of the mechanisms of hair cell stimulation need revision. There is now evidence in a reptile and mammals that the tectorial membrane is not stiff enough to act as a stationary shearing partner for the hair cells during basilar-membrane motion, but that it contributes its mass to a resonance system (Manley et al. 1988; Zwislocki et al. 1988). If the stimulus to the hair cells depends on a resonance of the tectorial membrane, there is no reason why hair cells over the basilar membrane should be more sensitive. 
Our data from both the chick and the starling indicate that, as in mammals, acoustically-active primary auditory afferents only innervate hair cells on the neural side of the auditory papilla. Considering the independent evolutionary origin of these two vertebrate classes from different groups of reptile ancestors, it is remarkable to find indications of a clear functional parallel between avian and mammalian hair-cell populations. The parallel evolution of such hair-cell populations suggests that there are fundamental properties of hair cells which lend themselves to a particular kind of division of labour (Manley 1986).

Acknowledgements. This work was supported by a grant to G.A.M. from the Deutsche Forschungsgemeinschaft, Sonderforschungsbereich 204 'Gehör'. We thank C. Köppl, H.-J. Leppelsack and $\mathrm{H}$. Oeckinghaus for commenting on an earlier version of the manuscript.

\section{References}

Boord RL, Rasmussen GL (1963) Projection of the cochlear and lagenar nerves on the cochlear nucleus of the pigeon. J Comp Neurol 120:463-471

Carroll RL (1987) Vertebrate palacontology and evolution. Freeman, New York

Chandler JP (1984) Light and electron microscopic studies of the basilar papilla in the duck, Anas platyrhynchos: I. The hatchling. J Comp Neurol 222:506-522

Cleveland WS (1979) Robust locally-weighted regressions and smoothing scatter plots. J Am Stat Ass 74:829-836

Cotanche DA, Saunders JC, Tilney LG (1987) Hair cell damage produced by acoustic trauma in the chick cochlea. Hearing Res 25:267-286

Düring M von, Andres KH, Simon K (1985) The comparative anatomy of the basilar papillae in birds. Fortschr Zool $30: 681-685$

Fermin CD, Cohen GM (1984) Developmental gradients in the embryonic chick's basilar papilla. Acta Otolaryngol (Stockh) 97:39-51

Firbas W, Müller G (1983) The efferent innervation of the avian cochlea. Hearing Res 10:109-116

Fischer FP, Köppl C, Manley G (1988) The basilar papilla of the barn owl Tyto alba: a quantitative morphological SEM analysis. Hearing Res 34:87-101

Gleich $O$ (in press) Auditory primary afferents in the starling: correlation of function and morphology. Hearing Res

Gleich O, Manley GA (1988) Quantitative morphological analysis of the sensory epithelium of the starling and pigeon basilar papilla. Hearing Res 34:69-87

Hudspeth AJ, Corey DP (1977) Sensitivity, polarity and conductance change in the response of vertebrate hair cells to controlled mechanical stimuli. Proc Natl Acad Sci USA $74: 2407-2411$

Jahnke V, Lundquist P-G, Wersäll J (1969) Some morphological aspects of sound perception in birds. Acta Otolaryngol (Stockh) 67:583-601

Klinke R, Pause M (1980) Discharge properties of primary auditory fibres in Caiman crocodilus; comparisons and con- trasts to the mammalian auditory nerve. Exp Brain Res $38: 137-150$

Klinke R, Smolders J (1984) Hearing mechanisms in caiman and pigeon. In: Bolis L, Keynes RD, Maddrell SHP (eds) Comparative physiology of sensory systems. Cambridge University Press, pp 195-211

Köppl C, Gleich O (1988) Cobalt labelling of single primary auditory neurons - an alternative to HRP. Hearing Res 32:111-116

Kuhn A, Müller CM, Leppelsack H-J, Schwartzkopff J (1982) Heart rate conditioning used for determination of auditory threshold in the starling. Naturwissenschaften $69: 245-246$

Leake PA (1977) SEM observations of the cochlear duct in Caiman crocodilus. Scan Electron Microsc 2:437-444

Lewis ER, Leverenz EL, Bialek WS (1985) The vertebrate inner ear. CRC Press, Boca Raton

Liberman MC (1982) Single-neuron labeling in the cat auditory nerve. Science 216:1239-1241

Liberman MC, Kiang NYS (1978) Acoustic trauma in cats: cochlear pathology and auditory-nerve activity. Acta Otolaryngol [Suppl] 358:5-63

Manley GA (1983) Auditory-nerve fibre activity in mammals. In: Lewis B (ed) Bioacoustics. Academic Press, London, pp 207-232

Manley GA (1986) The evolution of the mechanisms of frequency selectivity in vertebrates. In: Moore BCJ, Patterson RD (eds) Auditory frequency selectivity. Plenum Press, New York London, pp 63-72

Manley GA, Gleich O, Leppelsack H-J, Oeckinghaus H (1985) Activity patterns of cochlear ganglion neurones in the starling. J Comp Physiol A 157:161-181

Manley GA, Brix J, Kaiser A (1987a) Developmental stability of the tonotopic organization of the chick's basilar papilla. Science 237:655-656

Manley GA, Schulze M, Oeckinghaus H (1987b) Otoacoustic emissions in a song bird. Hearing Res 26:257-266

Manley GA, Yates G, Köppl C (1988) Auditory peripheral tuning: evidence for a simple resonance phenomenon in the lizard Tiliqua. Hearing Res 33:181-190

Manley GA, Brix J, Gleich O, Kaiser A, Köppl C, Yates G (in press) New aspects of comparative peripheral auditory physiology. In: Syka J (ed) Auditory system - structure and function. Plenum Press, London New York

Manley GA, Gleich O, Brix J, Kaiser A (in press) Functional parallels between hair-cell populations of birds and mammals. In: Duifhuis H, Horst JW, Witt HP (eds) Basic issues in hearing. Academic Press, London

Mountain DC (1986) Electromechanical properties of hair cells. In: Altschuler RA, Bobbin RP, Douglas WH (eds) Neurobiology of hearing: the cochlea. Raven Press, New York, pp 77-90

Palmer AR, Wilson JP (1981) Spontaneous and evoked acoustic emissions in the frog Rana esculenta. J Physiol 324:66P

Pujol R, Carlier E, Devigne C (1978) Different patterns of cochlear innervation during the development of the kitten. $J$ Comp Neurol 177:529-536

Rebillard M, Pujol R (1983) Innervation of the chicken basilar papilla during its development. Acta Otolaryngol (Stockh) 96:379-388

Robertson D (1982) Effects of acoustic trauma on stereociliar structure and spiral ganglion cell tuning properties in the guinea pig cochlea. Hearing Res 7:55-74

Robertson D (1984) Horseradish peroxidase injection of physiologically characterized afferent and efferent neurones in the guinea pig spiral ganglion. Hearing Res 15:113-121

Schermuly L, Klinke R (1985) Change of characteristic frequen- 
cies of pigeon primary auditory afferents with temperature. J Comp Physiol A 156:209-211

Schermuly L, Klinke R (in press) Single-fibre staining of infrasound-sensitive neurones in the pigeon inner ear. In: Syka $\mathrm{J}$ (ed) Auditory pathway - structure and function. Plenum, New York

Schermuly L, Göttle K-H, Klinke R (1983) Little ototoxic affect of Furosemide on the pigeon inner ear. Hearing Res $10: 279-282$

Smith CA (1985) Inner car. In: King AS, McLeland J (eds) Form and function in birds, vol 3. Academic Press, London, pp 273-310

Spoendlin $H$ (1978) The afferent innervation of the cochlea. In: Naunton RF, Fernandez C (eds) Evoked electrical activity in the auditory nervous system. Academic Press, New York, pp 3-19
Takasaka T, Smith CA (1971) The structure and innervation of the pigeon's basilar papilla. J Ultrastruct Res 35:20-65

Tilney MS, Tilney LG, DeRosier DJ (1987) The distribution of hair cell bundle lengths and orientations suggests an unexpected pattern of hair cell stimulation in the chick cochlea. Hearing Res 25:141-151

Whitehead MC, Morest DK (1985a) The development of innervation patterns in the avian cochlea. Neuroscience 14:255-276

Whitehead MC, Morest DK (1985b) The growth of cochlear fibers and the formation of their synaptic endings in the avian inner ear: a study with the electron microscope. Neuroscience 14:277-300

Zwislocki J, Slepecky N, Cefaratti L (1988) Tectorial-membrane stiffness and hair-cell stimulation. Abstracts 11th Mtg Assoc Res Otolaryngol, p 170 